\title{
FALTA DEBATE
}

Vinicius de Figueiredo

$(\mathrm{UFPR} / \mathrm{CNPq})^{l}$

Nos últimos vinte anos, a comunidade de pós-graduação em Filosofia cresceu a olhos vistos, trazendo consigo fenômenos como a diversificação das pesquisas, a heterogeneidade de interesses e de formação, além da ampliação da demanda por recursos das agências financiadoras. ${ }^{2}$ Esse crescimento trouxe muitas mudanças. A mais substancial e que se constata a olhos vistos reside em que a geração que está sucedendo a de nossos professores é muito mais numerosa e, embora sem ter por ora produzido expressões públicas à altura, sem dúvida ganhou em massa. Há muito mais gente que mexe com Filosofia no Brasil hoje em dia que antes.

Nada sugere que este processo irá desacelerar. Ao contrário: o crescimento promovido pela demanda interna ao meio acadêmico será provavelmente acompanhado por políticas do Ministério da Educação e por iniciativas do setor privado (mantenedoras, mercado editorial) voltadas também para a formação e requalificação de professores da disciplina no ensino médio. Nesse

1 Este texto foi elaborado a partir de notas tomadas para a mesa Filosofia no Brasil: Perspectivas no Ensino, na Pesquisa e na vida pública, coordenada por Ivan Domingues no XVII Congresso da SIF (Salvador, outubro de 2013). Agradeço a Edgar Marques, Vilma Aguiar e José Szabo pela leitura prévia e sugestões. Para se ter uma ideia desse crescimento, no final de 2001/2003, a área da Filosofia possuía 26 Programas Associados com a seguinte distribuição: 6/NE; 11/SE; 2/CO; 7/SU. Desses programas, 12 tinham nota 3; oito programas, nota 4; três programas, nota 5 e 3 com nota 6 (cf. PERINE, M. "Situação da pósgraduação em Filosofia no Brasil. Triênio 2004/2006”. Sapere Aude, Belo Horizonte, pp. 96-106, 1은 sem. 2010). Hoje, são 41 Programas, distribuídos por todas as regiões. Outro contraste se verifica na comparação do número de participantes dos Encontros Nacionais da ANPOF, realizados desde 1984. No Encontro Nacional de outubro de 2002, em São Paulo, foram apresentados aproximadamente 800 trabalhos, em 17 salas reservadas para as atividades, com 24 Programas credenciados (Apud: ÉVORA, F. "Mora na Filosofia". Entrevistada em matéria assinada por Wanda Jorge. Jornal da UNICAMP, ano XVII, nr. 194, pp. 14-20 out. 2002). Dez anos depois, no XV Encontro realizado em outubro de 2012 em Curitiba, foram apresentados aproximadamente 1700 trabalhos, em 45 salas paralelas, com o envolvimento de 40 Programas Associados. 
novo cenário, surgirão oportunidades para o aparecimento e consolidação de novos tipos de publicação além das tradicionais (magazines de divulgação, bibliografia não especializada, obras de auxílio ao professor do ensino médio, seleção do livro didático em Filosofia etc.). Essa heterogeneidade faz apostar no tão alentado aparecimento de um público leitor de Filosofia no Brasil, antecipado pela aventura de que participaram nossos professores com a coleção Os pensadores, nos anos 70. Com esta diferença: a escala se ampliou muito. O primeiro livro de Filosofia no lar de muitos brasileiros já não será o Platão, Espinosa ou Wittgenstein da coleção idealizada e empreendida de forma pioneira por José Américo Pessanha. Será uma obra didática, a qual, em conformidade com as diretrizes elaboradas pelo Ministério da Educação para o Plano Nacional do Livro Didático para a área, apresentará questões de Filosofia em seu curso histórico tendo em vista o estudante do ensino médio. As chances de o livro ser lido por um público mais amplo se tornaram maiores.

Neste quadro, o conjunto da pós-graduação em Filosofia desempenha um papel decisivo. Ao renovar os quadros responsáveis pelo que há de mais relevante na produção filosófica brasileira e formar futuros professores do ensino médio, institui os parâmetros de um debate que se expande para dentro e fora dos programas hoje existentes. Por certo, os programas e os professores/ pesquisadores que atuam neles não fazem isso sozinhos. As agências de avaliação e fomento desempenham aí um papel central. Dir-se-ia até um papel "originário": se entre nós a pós-graduação em Filosofia começa a adquirir ares de sistema, isso se deu graças a políticas públicas que têm tido continuidade no curso das últimas três décadas. Visto que a implementação dessas políticas teve como motor principal a distribuição de recursos e apoio institucional das mencionadas agências aos programas existentes e àqueles que foram surgindo no curso do tempo, valerá a pena arriscar algumas observações sobre as relações, nem sempre pacíficas, entre as agências e as universidades, nas quais se produz hoje em dia o que há de substancial em Filosofia no Brasil. Esse enfoque poderá contribuir para enriquecer o debate que anima o presente dossiê.

Como registro preliminar, é útil observar que a discussão sobre o atual processo de avaliação da pós-graduação em Filosofia no Brasil comporta níveis de reflexão analiticamente distintos. Num nível mais geral, a maioria da comunidade filosófica brasileira parece estar de acordo sobre o acerto da direção tomada pela política de avaliação em curso há mais de trinta anos pelo Ministério da Educação. Essa direção, comum ao conjunto das áreas representadas na CAPES, exprime-se no princípio geral de que a avaliação estimula e apoia a ampliação e a qualificação de cursos de pós-graduação com 
base em parâmetros de excelência elaborados em debate com as respectivas áreas e com sua coordenação geral, nas instâncias superiores de decisão das agências. Embora sujeita a críticas e questionamentos, essa ideia prevalece. A principal razão disso está, como já dito, no fato de que o estágio em que se encontra atualmente a comunidade acadêmica filosófica brasileira é, em grande medida, resultado das políticas públicas em relação ao sistema superior de ensino, políticas nas quais o sistema de avaliação desempenha um papel preponderante. É um resultado considerável. Em comparação com outros países nos quais inexistiu essa coordenação entre burocracia, fins públicos e academia ou em que assumiu formas diversas, no Brasil se chegou a um nível de cuidado com os textos, com a literatura e com as questões filosóficas que constitui não só base para a formação de novos professores/pesquisadores, como para a recepção crítica de contribuições originais que porventura sejamos capazes de realizar. Guido de Almeida, em texto publicado neste dossiê, comenta a lenta e trabalhosa formação, com boa parte de sua geração, da figura do scholar em Filosofia, praticamente inexistente até a década de 1960. Os resultados expressivos obtidos nesta tarefa não seriam possíveis sem o apoio das políticas de fomento e avaliação.

Outra ordem de questões reside na indagação, sempre bem-vinda, sobre se os critérios em curso para levar a cabo este princípio geral são os mais apropriados, ou se não deveriam ser em parte substituídos ou complementados por outros critérios, mais condizentes com formas de produção da Filosofia desprestigiadas pelo modelo atual. Certamente não é difícil apontar anomalias na pauta das agências. E não se poderia esperar outra coisa, quando se tem em conta que essa comunidade se ampliou e se diversificou intensamente nos últimos vinte anos. Aqui, as dificuldades concernem à maior ou menor sintonia entre as agências e a comunidade, cujos interesses e possibilidades só se tornam homogêneos quando viram alvo das quantificações exigidas pelo sistema avaliativo.

Um terceiro nível de reflexão, bem próximo mas diferente do anterior, reside em examinar em que medida o princípio da distribuição de recursos conforme parâmetros de excelência, por mais sintonizados que estejam com a comunidade, não direciona de modo excessivo, quando não irrefletido, a forma que assume a produção filosófica em curso. O perfil do professor/pesquisador em Filosofia no Brasil alterou-se de forma significativa nesse período. Essa mudança se deve essencialmente ao fato de que, hoje em dia, o estudante de graduação e futuro pesquisador se encontra desde o início de sua formação orientado por expectativas cuja ratificação depende, em última análise, das instâncias que distribuem os recursos. Mesmo supondo um quadro no qual 
o sistema de avaliação seja consensual e mobilize mecanismos de consulta à comunidade, permanece o fato de que as expectativas a serem atendidas para assegurar o êxito dos programas e dos pesquisadores é sempre uma aposta - e não necessariamente a melhor. Efeitos positivos vão de par com o aparecimento de anomalias. Um fenômeno que ilustra bem o ponto é o enfraquecimento progressivo de formas de produção intelectual que já se mostraram de grande relevância entre nós. É o caso da tradição do ensaio filosófico, que, embora já tenha logrado contribuições inestimáveis com intelectuais como Benedito Nunes ou Bento Prado Jr., dentre outros, encontra dificuldades de acomodação nos tipos de produção valorizados pelo sistema, excessivamente orientado pela equivalência entre profissionalização e especialização da reflexão filosófica. Tomados isoladamente, o especialista e o ensaísta são antípodas. Mas por que deveríamos sacrificar um em detrimento do outro, se, como já deram prova disso alguns dentre nós, eles podem combinar-se muito bem na mesma trajetória intelectual?

Na prática, esses três níveis de questões encontram-se articulados. Assim, é inevitável que a instituição de parâmetros de excelência como instrumento de distribuição de recursos, princípio bem-vindo que pauta a política pública, não incida sobre a produção científica dos agentes, orientando as estratégias de reconhecimento e êxito em detrimento de formas de investigação e produção igualmente "produtivas", mas que pouco condizem com as expectativas das agências de fomento. Se é difícil imaginar o que poderia substituir-se à ideia de que programas e pesquisadores sejam recompensados com implementação de bolsas de estudo e apoio institucional conforme a satisfação de quesitos acadêmicos divulgados publicamente, isso não elide a necessidade de refletirmos sobre os parâmetros que definem as modalidades de qualidade admitidas pelas políticas de fomento e, especialmente, sobre o grau de constrangimento que isso impõe à expressão da Filosofia, cuja história sempre admitiu formas as mais diversificadas.

Cogitar sobre isso equivale, feitas as contas, a qualificar o que se entende por qualidade. As instituições de avaliação e fomento realizam esse tipo de reflexão nos limites impostos pela formulação de qualquer política pública, isto é, tomando como fatores qualitativos tendo em vista seu resultado em números. Essa tradução é sempre imperfeita. A contribuição de Marilena Chauí a este dossiê aponta algumas das anomalias a que se sujeita todo processo de avaliação em macroescala. Da fabricação de citações recíprocas à tendência de publicar seja o que for a cada ano, a fim de assegurar a cesta mínima exigida do "homo Lattes", passando pela confusão em assimilar internacionalização com a proliferação de artigos em inglês que permanecem 
invisíveis no debate, sobram razões para concluir que, por bem-vindo que seja como elemento de indução de práticas científicas de qualidade em grande escala, o sistema de avaliação também possui sua alienação. Constatá-la não é opor-se às agências e sim saber que elas não devem ser abandonadas à própria sorte. E não abandoná-las à própria sorte significa realizar também e especialmente fora do padrão de sua racionalidade típica as atividades cotidianas de ensino e pesquisa, conferindo-lhes aquela perspectiva condizente com a ideia de "vida pública". Nesta discussão, um ponto central reside em não assimilar irrefletidamente os mecanismos de avaliação da comunidade pelas agências com a dinâmica por meio da qual transcorre o autoconhecimento da comunidade filosófica. Embora concretamente articulados, esses dois planos são distintos; e é bom ter sua diferença em conta, para não se correr o risco de, sem querer, pretender-se substituir um ao outro, quando na verdade são insubstituíveis. São complementares, não excludentes.

Mas o que significa "autoavaliação" ou "autoconhecimento" da comunidade? Nada muito diferente do que fazemos dia após dia. A bibliografia ao fim de um texto (dissertação, tese, capítulo de livro, livro ou artigo) reivindica a inscrição do seu autor em um debate. A literatura utilizada em um curso de graduação ou de pós revela escolhas da mesma ordem. Isso também vale para participações em encontros e em congressos. Nosso cotidiano é fazer avaliações, avaliamos o tempo todo. Já existe em curso uma autoavaliação da comunidade. O problema é que ela ainda é tímida, se pensarmos no conjunto de programas de pós-graduação em Filosofia existentes no Brasil. Lemo-nos pouco, debatemos pouco uns com os outros. Não constitui fato isolado que na seção "Estante", criada há três anos na página da ANPOF, e que opera com contribuições espontâneas de professores e estudantes, haja livros publicados recentemente por pesquisadores renomados que não receberam sequer uma resenha. Não é significativo que as melhores expressões de nosso meio não sejam objeto de crítica e discussão, como seria de se esperar, quando o assunto é Filosofia? Ao mesmo tempo, seria vão esperar que a forma e o fundo desse tipo de debate fossem realizados no nível em que transcorrem as ações das agências de fomento. Nelas, pode-se pleitear que a publicação de resenhas críticas tenha seu devido valor reconhecido, o que não ocorre hoje em dia. Mas cabe aos membros da comunidade o empenho de redigi-las, de debater uns com os outros. ${ }^{3}$

3 Um outro exemplo das limitações intrínsecas às agências deu-se na reunião da CAPES com os coordenadores de Programas realizada em Brasília em outubro de 2011. Os professores Danilo Marcondes e João Carlos Salles, então coordenadores da área de Filosofia, chamavam a atenção para a dificuldade 
O que, então, faz falta à Filosofia no Brasil não é avaliação, formulação de políticas indutoras, apoio a novos programas etc. Isso já temos, e, por mais que seja sempre matéria de crítica, correção e inovação, não é pouca coisa. Mas, afora exceções de praxe, a ampliação do sistema de pós-graduação ainda não produziu o correspondente debate de ideias. A expressão mais objetiva da leitura e crítica que realizamos de nós por mesmos transcorre no outro plano, isto é, sob a forma de avaliação da comunidade filosófica pelas agências de fomento: é ali que, como consultores, lemos (na medida do necessário) e julgamos uns aos outros, mas resguardados pelo anonimato e constrangidos pelos prazos de emissão dos pareceres. Embora os sujeitos sejam os mesmos, o contexto é completamente diferente, como são diferentes os resultados. Essa forma de leitura e crítica não pode tornar-se pública por definição. E, na falta da racionalidade sedimentada pelo debate em torno dos textos e posições assumidas publicamente, o trabalho urdido no dia a dia, mesmo se ratificado pelas instâncias de avaliação, não conseguirá ultrapassar expectativas elaboradas pelas próprias agências, que, por mais capilares que sejam, não saberão redundar em consciência autorrefletida dos que mexem com Filosofia entre nós. A diferença de contextos define diferentemente a atuação dos sujeitos. Seria ingênuo esperar que dissonâncias e críticas com prazo para desaparecer, em um contexto marcado pela disputa entre recursos (eis o sentido efetivo da célebre curva de Gauss) produzam alguma novidade substancial diante dos imperativos sistêmicos que preenchem a pauta das agências. Pode bem acontecer que elas continuem a avaliar com competência uma produção acadêmica cada vez mais numerosa e ao mesmo tempo tímida publicamente.

Se o raciocínio for válido, pode-se concluir que dar alcance público à Filosofia não passa por sobrecarregar ainda mais os mecanismos de avaliação, nem, de outro lado, imaginar que seja possível ou desejável ignorá-los. Tampouco passa por aderir à ideia de que haja uma Filosofia nativa à espera de nossa vocação. Imaginar que o alcance público do trabalho intelectual possa depender da matéria - nacional ou estrangeira - da reflexão seria outro modo de no fundo furtar-se ao problema. O alcance público do pensamento reside na forma que ele assume para o conjunto da comunidade acadêmica tomada em sentido amplo e da sociedade em que ela se inscreve. Isso ocorrendo, a

de aferir qualitativamente o número expressivo de capítulos de livro produzidos na área. De fato, como fazê-lo criteriosamente, sem convocar uma supercomissão para dar conta da tarefa? Mesmo se isso fosse factível, não correríamos o risco de querer criar por decreto aquela "esfera pública" que deve subsistir sem o concurso das agências? 
pertinência cultural e a atualidade dos temas e problemas debatidos estará assegurada. Se há razões para crer que essa forma pública encontra nas transformações por que vem passando essa sociedade (um pouco menos desigual e autoritária que antes) as condições para encontrar expressões mais condizentes consigo, elas não irão frutificar, caso o debate entre quem faz Filosofia no Brasil não ultrapasse o diminuto nível atual.

Neste ponto, a existência de entidades como a Associação Nacional de Pós-Graduação em Filosofia, a ANPOF, tem um papel importante a cumprir. Ações como o aprimoramento dos grupos de trabalho, a circulação de informações e conhecimento, a promoção de encontros nacionais e o estímulo à colaboração interinstitucional (o que requer um trabalho conjunto com as agências, estimulando experiências como o PROCAD e similares) favorecem, todas elas, que o debate interno à comunidade filosófica nacional se intensifique e transborde de nossas certezas acadêmicas habituais. Some-se a isso o fenômeno representado pela volta da Filosofia ao ensino médio, com todos os desafios que traz consigo. A despeito da pouca qualificação média dos docentes (muitos dos quais não formados em Filosofia), as condições precárias em muitas escolas, a questão salarial, o fato é que a volta da Filosofia ao ensino médio pode sem dúvida trazer consigo o adensamento crítico do debate filosófico, quando não simplesmente pela ampliação e familiarização dos estudos filosóficos na dinâmica da formação de futuros cidadãos. Participar no papel que nos cabe na contribuição que a universidade pode fornecer à consolidação qualificada da Filosofia no ensino médio é beneficiar-se das implicações que esse fenômeno acarreta, a mais relevante delas sendo exatamente o surgimento de um público leitor ligado à Filosofia muito mais amplo do que existiu por aqui até o momento. Embora não haja como antecipar qual molde de intelectual essa aventura nos reserva nem que figuras ele admite, é certo que quem faz Filosofia no Brasil não poderá furtarse a fazê-lo um pouco mais com os outros. 